\title{
La producción agrícola de la paja toquilla en Ecuador, el flujo productivo artesanal y la formación de precios
}

\section{The agricultural production of toquilla straw in Ecuador, the artisanal productive flow and the formation of prices}

\author{
María Caridad Mederos Machado ${ }^{1}$, Carlos Eloy Balmaseda Espinosa ${ }^{1}$, Denisse Tatiana Suárez Yagual $^{1}$ y \\ Maritza Gisella Paula Chica ${ }^{1}$ \\ ${ }^{1}$ Universidad Estatal Península de Santa Elena, Ecuador \\ *mariacamederos@gmail.com
}

DOI: https://doi.org/10.26871/killkanatecnica.v4i2.688

\begin{abstract}
Resumen
La paja toquilla o Carludovica Palmata se cultiva en zonas montañosas como en la Costa y Oriente por ser zonas donde el clima es húmedo. Es una especie de palmera (de tejido fibroso), crece en forma silvestre en los bosques tropicales de las regiones Occidental y Oriente, y en zonas ubicadas a una altitud promedio de 100 a 180 metros. La diversidad de este cultivo no ha tenido expansión a otros lugares del país, por no poseer las características climáticas que este necesita. La paja toquilla, juega un papel importante en la economía de diversos grupos o asociaciones establecidas a nivel nacional, constituyendo en una fuente de ingreso para cada una de las familias. El objetivo del presente artículo es realizar una caracterización socio-productiva de la producción de paja toquilla, especialmente el flujo productivo artesanal y análisis de los elementos que intervienen en la formación de los precios de esta materia prima usada en la confección del sombrero, patrimonio de la humanidad y otros productos de consumo. Mediante instrumentos de investigación como la encuesta, la observación y la entrevista se puso llegar a conclusiones logrando establecer los nuevos diagramas de flujo de la producción artesanal de la paja toquilla, así como la formación del precio. En conclusiones, se obtiene un diagnóstico que permite tomar decisiones en la comuna.
\end{abstract}

Palabras clave: flujo de producción, paja toquilla, formación del precio.

\begin{abstract}
Toquilla straw or Carludovica Palmata is grown in mountainous areas such as the Coast and the East as they are areas where the climate is humid. It is a species of palm tree (with fibrous tissue), it grows wild in the tropical forests of the Western and Eastern regions, and in areas located at an average altitude of 100 to 180 meters. The diversity of this crop has not expanded to other parts of the country, because it does not have the climatic characteristics that it needs. Toquilla straw plays an important role in the economy of various groups or associations established at the national level, constituting a source of income for each of the families. The objective of this article is to carry out a socio-productive characterization of the production of toquilla straw, especially the artisanal productive flow and analysis of the elements that intervene in the formation of the prices of this raw material used in the making of the hat, heritage of humanity and other consumer products. Through research instruments such as the survey, observation and interview, it was possible to reach conclusions, establishing the new flow diagrams of the artisanal production of toquilla straw, as well as the formation of the price. In summary, a diagnosis is obtained that allows decisions to be made in the commune.
\end{abstract}

Keywords: production flow, shawl straw, price formation.

\section{INTRODUCCIÓN}

A inicios del siglo XX los artículos y productos de paja toquilla (CarludovicaPalmata) eran altamente demandados en Estados Unidos y Europa, tanto así que en el año 1944 y 1946, el sombrero de paja toquilla llegó a ser el primer producto de exportación del país, donde la habilidad de tejer se convirtió en un bien representativo de la identidad cultural del Ecuador, usado desde la época de los aborígenes [1].
El 5 de diciembre del 2012, en París, se proclamó al tejido del sombrero de "paja toquilla" como "Patrimonio Cultural Inmaterial de la Humanidad" [2].

La paja toquilla, juega un papel importante en la economía de diversos grupos o asociaciones establecidas a nivel nacional, constituyendo en una fuente de ingreso para cada una de las familias, este es el caso de la comuna Barcelona, ubicada en la provincia de Santa Elena donde prevalece 
la producción de fibra de paja toquilla, en la que es una de las principales actividades productivas. Anteriormente la población de la comuna Barcelona se dedicaba a producir y tejer pero por factores negativos tanto de precios, comercialización, desempleo, migración, se limitaron solo a la producción [3].

La presente investigación trata de responder a la pregunta: ¿Qué características tiene el proceso productivo de la paja toquilla en la comuna Barcelona?

$\mathrm{Su}$ objetivo general es precisar el flujo producción de paja toquilla en la comuna Barcelona y establecer el mecanismo de formación del precio de sus producciones.

La investigación parte del criterio de que la caracterización socioeconómica, vincula a la empresa y el campesino, relacionados en la producción que se ha establecido se analizan:

- Duración del ciclo de producción. Tiempo de trabajo necesario (TTN)

- Mano de obra.

- Mantenimiento de la producción.

- Cantidad de producto que se ha producido.

- Gastos que se efectuaron en la producción.

- Precio del bien en los mercados.

- Ingresos obtenidos en la venta del bien.

La metodología de la caracterización socioeconómica es desarrollar y utilizar datos socioeconómicos en comunidades representativas [4].

La paja toquilla es una especie de palmera (de tejido fibroso), cuyas hojas en forma de abanico salen desde el suelo, sostenidas por largos pecíolos cilíndricos, sus hojas son anchas y cada una de estas alcanzan de dos a tres metros de largo, el exterior de las hojas son verde color verde, su centro es de color marfil o blanco perla y es la parte donde se obtiene la paja para la elaboración de los sombreros. La Carludovica Palmata crece en forma silvestre en los bosques tropicales de las regiones Occidental y Oriente, en zonas ubicadas a una altitud promedio de 100 a 180 metros sobre el nivel del mar con temperaturas que fluctúan entre $\operatorname{los} 22^{\circ} \mathrm{C}$ y $26^{\circ} \mathrm{C}$. Sus suelos se caracterizan por ser catalogados de arcillosos.

La producción de paja toquilla se realiza en cualquier época del año y existen sembríos durante todo el año en zonas como Montecristi, Jipijapa, Barcelona, Dos Mangas entre otros [1].

La Cordillera Chongón - Colonche es una de las zonas de gran diversidad de cultivo de paja toquilla, considerando que el Ecuador posee zonas húmedas y un clima favorable que permite la siembra de la planta y de ahí parte las diferentes zonas donde se produce esta fibra como es la provincia del Guayas, Santa Elena y Manabí con un total de hectáreas de 77.000, otras de las zonas donde se cultiva la paja toquilla es la comuna Chachis o Cayapas ubicada en la provincia de Esmeraldas, sin embargo se considera que este cultivo no puede sembrarse en zona secas porque al final la materia prima no va a ser apta para darle un valor agregado a la misma [1].

\section{A. La paja toquilla en la producción agrícola del Ecua- dor}

La producción de la paja toquilla en el Ecuador tiene sus inicios desde los tiempos de la colonia, donde esta fibra era utilizada por los indígenas para prendas y actividades de caza, la Carludovica Palmata se cultiva en zonas montañosas como en la Costa y Oriente por ser zonas donde el clima es húmedo, cálido y brumoso entre estas zonas se encuentran Santa Elena, Manabí Guayas, Esmeraldas y Morona Santiago.

La diversidad de este cultivo no ha tenido expansión a otros lugares del país, por no poseer las características climáticas que este necesita, considerando que la zona más sobresaliente de paja toquilla es la provincia de Manabí.

No se precisa aun la fecha en que surgen las artesanías de paja toquilla, por lo que la actividad toquillera se consolidó en el siglo XVII cuando decayó la producción de algodón y los europeos lo demandaron como un sustituto del paño[5].

TABLA I: Nombre de la paja toquilla en diferentes países

\begin{tabular}{ll}
\hline País & Nombre \\
\hline Colombia & lucaica, murrapo, palama iraca \\
Guatemala & palmilla, junco \\
Costa Rica & $\begin{array}{l}\text { chidra } \\
\text { Panamá }\end{array}$ \\
$\begin{array}{l}\text { guachivan, atadero, bellota, palmita, palma som- } \\
\text { brero Panamá. }\end{array}$ \\
Brasil & toquilla, bobonaje. \\
Bolivia & jipi-japa \\
\hline
\end{tabular}

\section{Metodología}

Este trabajo es una investigación no experimental, descriptiva, en la que se describen las características del proceso de la paja toquilla, a partir de las encuestas, entrevistas y observaciones realizadas en las familias o asociaciones establecidas en la comuna Barcelona.

El uso de estas técnicas permitió observar cada una de las etapas de la producción de la paja toquilla, así como los acontecimientos cotidianos que caracterizan este proceso.

\section{RESUltados}

En los meses de diciembre a mayo se presenta la época invernal, con una temperatura de $34^{\circ}$ y $36^{\circ}$, la época seca se presenta entre junio y julio, la presencia de neblina se da en julio y agosto.

Generalmente las familias de la comuna Barcelona se dedican a la agricultura, por ser una de las fuentes de ingreso y sustento diario, su nivel de educación solo es primario, el tipo de vivienda es mixta, la salubridad es baja por la falta de subcentro y la disponibilidad de los mismos. [6]

En la comuna Barcelona existen cuatros asociaciones establecidas en la producción de paja toquilla. 
Las actividades que realiza generalmente el productor están relacionadas con la transformación de la materia prima en un bien final, donde relaciona procesos productivos artesanales y en menor escala la aplicación de tecnología, por lo cual no se involucran en temas administrativos ni de mercados.

En la comuna Barcelona en el año 2010 se encontraban establecidos 138 toquilleros, en el año 2016 se encuentran 105 productores, la cantidad de productores ha disminuido por la fuerte migración campesina y el $80 \%$ y $90 \%$ de sequías que se han presentado durante estos años. Actualmente existen 53 productores, estos a su vez poseen hectáreas de terrenos en las montañas de la siguiente manera:

- 12 productores poseen más de 5 hectáreas de terreno

- 41 productores poseen hectáreas que varían desde 1 hasta 4 hectáreas de terreno.

- $\quad$ El precio del sombrero oscila de \$50 a \$1500 y los más económicos de $\$ 50$ a $\$ 70$.

\section{A. Tiempo de trabajo necesario (TTN)}

- Un sombrero de cuatro vueltas se realiza en un día.

- Un sombrero de más de 20 vueltas se realiza en 7 9 meses, estos son los que generalmente elabora la empresa.

- Siete meses es el tiempo para la elaboración de un sombrero.

\section{B. Formación del precio}

Se considera que los costos del precio del mazo se compran en $\$ 10$ con 30 cogollos, cada sombrero se elabora con 24 cogollos de modo que en la formación del precio el trabajo agrícola y de procesamiento del producto terminado no se contemplan como definitorios para conformar el precio.

El elemento definitorio para decidir el precio de un sombrero solo se circunscribe al trabajo artesanal de creación a partir de la materia prima ya elaborada, y especialmente al TTN (tiempo de trabajo necesario) para realizar cada unidad, la creatividad del artesano tejedor, grosor y color de la fibra con que se teje, son elementos importantes para la valoración del sombrero.

Sin embargo, es ínfimo en ese precio el significado de las labores previas a la llegada de materia prima a las manos del tejedor. Por tal razón es importante conocer el proceso artesanal de procesamiento de la materia prima.

En la comuna Barcelona se han establecidos algunas denominaciones por parte de productores y artesanos y son:

- Las mujeres artesanas que se encargan de limpiar la paja toquilla por cada "ocho" su valor es de \$1.25 quiere decir que por procesar cada cogollo le pagan 0,01 ctvs.

\section{Calculo:}

$\$ 1,25 / 112$ cogollos $=0,01$ ctvs $\times 112$ cogollos $=\$ 1,12$.

El $\$ 1,12$ es el valor real por la limpieza de cada cogollo por lo que se deduce que por la mano de obra adquieren 0,13 ctvs
TABLA II: Terminología de producción

\begin{tabular}{cc}
\hline Término & Cantidad \\
\hline 1 mano & 4 cogollos \\
1 real & 14 cogollos \\
1 peseta & 28 cogollos \\
$1 / 2$ ocho & 56 cogollos \\
un ocho & 112 cogollos \\
1 tongo & 96 tallos \\
1 bulto & 2976 cogollos \\
\hline
\end{tabular}

- Las mujeres artesanas que se encargan de limpiar la paja toquilla por cada "ocho" su valor es de $\$ 1.25$ quiere decir que por procesar cada cogollo le pagan 0,01 ctvs.

\section{Calculo:}

$\$ 1,25 / 112$ cogollos $=0,01$ ctvs $\times 112$ cogollos $=\$ 1,12$.

El $\$ 1,12$ es el valor real por la limpieza de cada cogollo por lo que se deduce que por la mano de obra adquieren 0,13 ctvs.

- $\quad$ El bulto que comercializan los artesanos a la Sierra es de $\$ 300$, se establece que un bulto tiene 2976 cogollos, es decir por cada cogollo le pagan 0,10 ctvs y por cada "ocho" le pagan $\$ 11,29$

\section{Calculo:}

1 tongo $=96$ cogollos $\mathrm{x} 31$ tongos $=2976$ cogollos que equivale a un bulto.

$\$ 300 / 2976$ cogollos $=0,10$ ctvs $\times 2976$ cogollos $=$ $\$ 297,60$.

TABLA III: Calculo de cada . ${ }^{\circ}$ cho"

\begin{tabular}{|cc|}
\hline $\begin{array}{c}\$ 300 \\
\mathrm{x}\end{array}$ & $\begin{array}{c}2976 \text { cogollos } \\
112 \text { cogollos }-1 \text { “ocho" }\end{array}$ \\
& $\$ 300 \times 112$ cogollos \\
\hline & 2976 Cogollos \\
& $=\$ \mathbf{1 1 . 2 9}$ \\
\hline
\end{tabular}

En el cálculo del bulto de paja toquilla le pagan 0,10 ctvs.por cada cogollo y su valor real es de $\$ 297,60$, se considera que $\$ 2,40$ es de la mano obra del artesano y con relación al cálculo de cada "ocho" su valor es de \$11,29.

TABLA IV: Cálculo de una hectárea de paja toquilla

\begin{tabular}{cc}
\hline \multicolumn{3}{c}{ Datos } \\
\hline 1ha & 35 cogollos \\
1 ocho & 112 cogollos \\
c/planta & 27 a 35 cogollos \\
\hline
\end{tabular}

Según datos obtenidos, se realizó el siguiente cálculo: 


\begin{tabular}{|c|c|}
\hline 1 planta & 27 cogollos \\
\hline \multicolumn{2}{|c|}{112 cogollos x 1 planta } \\
\hline \multicolumn{2}{|c|}{27 Cogollos } \\
\hline \multicolumn{2}{|c|}{4 plantas $x 35=\mathbf{1 4 0}$ plantas } \\
\hline 1 planta & 35 cogollos \\
\hline $\mathrm{x}$ & 112 cogollos \\
\hline \multicolumn{2}{|c|}{112 cogollos x 1 planta } \\
\hline \multicolumn{2}{|c|}{35 Cogollos } \\
\hline 3 pla & 5 plantas \\
\hline
\end{tabular}

En el cálculo anterior se puede observar que en 27 cogollos se obtienen 140 plantas y en 35 cogollos se obtienen 105 plantas, en una hectárea.

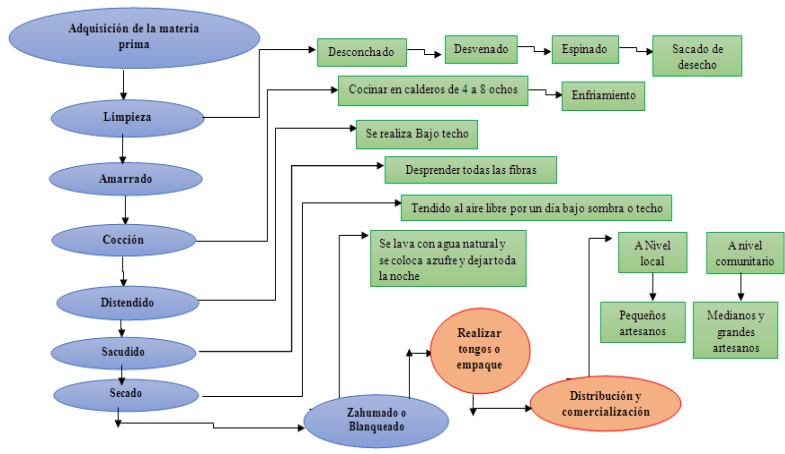

Fig. 1

Como se aprecia, se desarrollan muchas actividades de alto nivel de especialización que no se consideran tecnológicas, sino que corresponden a saberes tradicionales populares que encierran un valor superior a lo que verdaderamente es ingresado por estos productores.

\section{COnClusiones}

La mayoría de la población de la comuna Barcelona solo tiene instrucción primaria, por lo que las familias se dedican a la agricultura, siendo preponderante la producción de paja toquilla, actividad que se ha transferido de generación en generación. El $25 \%$ de la población se dedica a la agricultura de ciclo corto, el $65 \%$ a la producción de toquillales y a su procesamiento, mientras que el $10 \%$ trabaja en fincas aledañas a la comunidad o en las diferentes comunidades del cantón Santa Elena.

La producción de paja toquilla requiere de mano de obra, sobre todo en el procesamiento, desde la cosecha hasta la comercialización. La comuna Barcelona tiene un proceso propio de producción. El proceso agrícola de la paja toquilla es realizado por las asociaciones establecidas en la comuna, sin embargo, las condiciones de trabajo no son adecuadas especialmente para las mujeres, pues no poseen equipos de protección para el cocinado, ni botiquín para primeros auxilios.

En su mayoría, las mujeres de la comuna dedican mucho tiempo y esfuerzo a la limpieza de la fibra, pero el precio que le pagan es muy bajo, por cada "ocho" que equivale a 112 cogollos reciben solo $\$ 1,25$, es decir, $\$ 0,01$ por cada cogollo.

De manera general, el precio que reciben los productores por sus productos se considera poco favorable y poco justo; por ejemplo, en Montecristi, Manabí, un sombrero de Montecristi es vendido a un precio de entre $\$ 50,00$ y $\$ 1500,00$, mientras que los productores comercializan el tongo de paja toquilla solo en $\$ 300$.

\section{REFERENCIAS}

[1] Chóez, T. Propuesta de Asociatividad para los artesanos que elaboran sombreros de paja toquilla en la comuna Bambil Deshecho dentro de la provincia de Santa Elena, Bambil Deshecho: s.n. Consultado el 18 de mayo del 2016. Disponible en: http://bibliotecas.upse.edu.ec/opac_css/index.php? lvl=notice_display\&id=3140 2013

[2] UNESCO. Patrimonio Inmaterial Cultural. Disponible en http://www.montecuadorhat.com/tag/paja-toquilla/ 2013

[3] Andrea Boero. "Diseño de Sistema de Calentamiento de Aire y Cámara de Secado para Paja Toquilla por Recuperación de Energía desde Hornos Artesanales de Cocción de la Paja”. Tesis de Grado. Facultad de Ingeniería en Mecánica y Ciencias de la Producción, Escuela Superior Politécnica Del Litoral. 2008

[4] Zambrano, B. Metodología en los diagramas de flujos. 2012

[5] Claudia Palacios, C. Los sombreros de paja toquilla un Producto Artesana Disponible en: http://www. definicionlegal.com/definicionde/Globalizacion.htm 2013

[6] Edwin Jiménez. "Mejoramiento del proceso de producción de la fibra natural paja toquilla para la elaboración de sombreros y otras artesanías en la comuna Barcelona de la península de Santa Elena "Escuela Superior Politécnica Del Litoral ESPOL disponible: https://www.dspace.espol.edu.ec/ bitstream/123456789/1573/1/3118.pdf 2005

[7] Jimbo, A. Valoración de costos, aplicación de costeo por Procesos para la producción de la paja toquilla en la Asociación "Teresita Esperanza de la comuna Barcelona, cantón Santa Elena, Provincia de Santa Elena, 2015:sn. Consultado el 31 de mayo del 2016. Disponible en: http://bibliotecas.upse.edu.ec/opac_css/ index.php?lvl=notice_display\&id=9517 2015

[8] Organización de la Naciones Unidas para la Agricultura y la Alimentación FAO. Genero y sistemas de pro- 
ducción campesinos. Lecciones de Nicaragua. Roma. 2005

[9] Proaño, F. Origen del sombrero Panamá Hats. Universidad San Francisco de Quito. 2013

[10] Ubilla, G. Creación del centro de diseño de paja toquilla para la asociación de mujeres artesanas agricultoras productivas emprendedoras libres-MAPEL, Santa Elena, 2014: s.n. Consultado el 19 de julio del 2016. Disponible en: http://bibliotecas.upse.edu.ec/opac_css/ index.php?lvl=notice_display\&id=4351 2014

Recibido: 6 de abril de 2020

Aceptado: 15 de junio de 2020 
